DOI 10.37882/2223-2982.2021.03-2.40

\title{
СМЕШАННОЕ ОБУЧЕНИЕ НА УРОКАХ РУССКОГО ЯЗЫКА В СРЕДНЕЙ И СТАРШЕЙ ШКОЛЕ: ИЗ ОПЫТА ПРИМЕНЕНИЯ
}

\section{MIXED LEARNING IN RUSSIAN LANGUAGE LESSONS IN MIDDLE AND HIGH SCHOOL: FROM THE EXPERIENCE OF USING}

\section{Tsvetkova}

Summary: The article highlights the issues of changes that have occurred in the educational process and in teaching Russian at school in our time. The article considers the experience of using mixed learning technologies as a way to effectively organize the educational process. A practical example of the implementation of models of mixed learning and forecasting of educational results is given.

Keywords: FSES, activity approach, problematization of learning, mixed learning, inverted class, station rotation, group work, computerization.

\author{
Цветкова Любовь Алексеевна \\ К.филол.н., преподаватель, ГБОУ «Школа №41 \\ им. Г.А. Тарана», г. Москва \\ tsvetkova.liubov1986@gmail.com
}

Аннотация: В статье освещены вопросы изменений, произошедших в образовательном процессе и в обучении русскому языку в школе в наше время. Рассматривается опыт применения технологий смешанного обучения, как способа эффективной организации образовательного процесса. Дан практический пример реализации моделей смешанного обучения и прогнозирования образовательных результатов.

Ключевые слова: ФГОС, деятельностный подход, проблематизация обучения, смешанное обучение, перевёрнутый класс, ротация станций, групповая работа, компьютеризация.
$\mathrm{B}$ наши дни сфера образования стремительно развивается, появляются новые технологии и методики, трансформируются традиционные методы, меняются подходы и формы. Эти трансформации обусловлены изменившейся социокультурной ситуацией и кардинальной перестройкой типа мышления у учащихся.

Законодательно все описываемые процессы были оформлены в виде Федерального государственного образовательного стандарта (ФГОС) нового поколения. Постепенный переход на его принципы поэтапно осуществляется с 2009 года.

\section{Что же принципиально изменилось?}

Традиционное учебное занятие строится из учёта задачи формирования знаний, умений, навыков (ЗУН), которые, по своей сути, представляют собой некий готовый продукт (готовые формулы, алгоритмы решения, образцы, устойчивые последовательности действий и тому подобное). Активную роль в этой системе играет учитель: он носитель информации, хранитель норм, пропагандист знаний. Ученик же является объектом образовательного процесса: его роль пассивна, учебные действия репродуктивны, а мотивационная составляющая для оценки успешности обучения практически не учитывается. Качество обученности в этом случае измеряется объёмом усвоенных знаний, степенью освоения умений и сформированностью определённого набора навыков. Ещё в недавнем прошлом такой подход был оптимальным и давал свои позитивные плоды (не случайно до сих пор бытует мнение, что советская модель образования была лучшей, даже в наши дни у неё найдётся немало поклонников и приверженцев).

Однако, со стремительным развитием информационной сферы, компьютеризацией и цифровизацией трансформировались и задачи, которые должно решить образование. Доступность информации и многократно возросшая скорость обмена данными сделали ситуацию, в которой учитель является единственным источником знаний и гарантом их достоверности, принципиально невозможной. Изменившийся тип мышления и восприятия информации (учёные говорят о феномене «клипового мышления», суть которого в том, что человек воспринимает мир не целостно, а как последовательность почти не связанных между собой событий) также повлиял на снижение эффективности традиционных методов и форм обучения. Таким образом, вектор развития в сфере образования был направлен в сторону разработки способов преодоления «мозаичности» восприятия и создания новых технологий и методик обучения, способных удовлетворить новым потребностям общества.

Одним из решений поставленных задач в отечественной школе стало внедрение технологий смешанного обучения («blended learning»). За названием методики скрывается сочетание, «смешивание», традиционных приёмов обучения и инновационных образовательных технологий, очной и дистанционной форм обучения, обучения с педагогом и самообразования. Впервые модели этой образовательной технологии стали применяться еще в 60ые годы XX века, терминологический аппарат методики был оформлен в конце 90х годов XX века. В от- 
ечественной педагогике «смешанное обучение» начало осваиваться сравнительно недавно, широко применяется преимущественно на уроках в начальном звене образовательных организаций. Однако опыт использования моделей смешанного обучения даёт пищу для размышления всему педагогическому сообществу и создаёт почву для усовершенствования и калибровки данной образовательной технологии.

В современной отечественной практике из существующих моделей смешанного обучения активно используются формы ротации станций (смены рабочих мест) и «перевёрнутый» класс. Обе модели позволяют выполнить задачи индивидуализации в процессе обучения, активизации роли ученика и создания эффективной образовательной среды (проблематизация обучения). «Перевёрнутый» класс предполагает перенос изучения теории в дистанционный режим (самостоятельное изучение дома), а на очном занятии проводится практическая отработка изученного материала, устранение пробелов в знаниях, а также усложнение выполняемых задач. На уроке «ротации станций» учащиеся успевают поработать фронтально с учителем, в парах или малых группах и индивидуально (в т.ч. в виртуальной образовательной среде), что обеспечивает динамичную и эффективную смену видов деятельности и форм обучения.

Как показывает практика, применение технологий смешанного обучения способствует повышению эффективности учебного процесса и на уроках русского языка в среднем и старшем звене, достижению не только предметных, но и метапредметных и личностных результатов. Стоит отметить, что «в системе школьного образования учебный предмет «Русский язык» занимает особое место: является не только объектом изучения, но и средством обучения. Как средство познания действительности русский язык обеспечивает развитие интеллектуальных и творческих способностей ребёнка, развивает его абстрактное мышление, память и воображение, формирует навыки самостоятельной учебной деятельности, самообразования и самореализации личности. Будучи формой хранения и усвоения различных знаний, русский язык неразрывно связан со всеми школьными предметами и влияет на качество усвоения всех других школьных предметов, а в перспективе способствует овладению будущей профессией». Именно по этой причине первостепенной задачей становится обеспечение высокого качества обученности учащихся по этому предмету, формирование компетенций, связанных с практическим применением получаемых знаний. Модели смешанного обучения, ориентированные на самостоятельность и активность учащихся в процессе обучения, на индивидуализацию и проблематизацию обучения, опирающиеся на деятельностный подход, вполне удовлетворяют обозначенным задачам.
В соответствии с ФГОС учебные занятия по русскому языку представлены следующими типами уроков: урок открытия нового знания, урок рефлексии, урок общеметодологической направленности, урок развивающего контроля. Традиционно занятия указанных типов включают в себя подробный разбор, обсуждение, систематизацию и контроль достаточно объёмной и сложной теории по разным разделам науки о языке, на которую опираются задания практической направленности. В связи с этим, несмотря на то, что на изучение русского языка типовая программа выделяет достаточно много часов (5ч в неделю - 5 класс; 6ч в неделю - 6 класс; 4ч. в неделю - 7,8 класс и Зч. в неделю - 9 класс), наблюдается дефицит времени для практической отработки учебного материала. Решить указанную проблему может модель «смешанного обучения» - «перевёрнутый класс». Применение этого метода освобождает до $80 \%$ урочного времени для решения задач, связанных с практическим применением знаний, с их анализом, синтезом и оценкой, иными словами, позволяет добиться выхода на новый качественный уровень решаемых задач (см. таксономию Блума). При этом не стоит путать технологию «перевёрнутого класса» с «дистанционным обучением». Отличие в том, что сохраняется принцип обучения «лицом к лицу» во время очного занятия в классе, меняется лишь содержание такого урока. Суть же метода в том, что изучение теории выносится на самостоятельное изучение дома, на очной встрече происходит практическое закрепление полученных знаний, устранение пробелов, корректировка и последующее углубление/усложнение содержания.

В рамках данной технологии подвергается переосмыслению содержание и структура домашнего задания. В связи с этим в переходный период (от традиционной системы к «перевёрнутому классу») педагогу необходимо выполнить два типа задач: внести методические коррективы содержательного плана и решить технические вопросы обеспечения домашнего задания. Самостоятельное изучение темы дома не должно сводиться к чтению теоретических статей учебника, правил, алгоритмов и выполнению упражнений на их отработку. Такое задание будет малоэффективно, потому что многое из теоретических сведений, изложенных в стандартном учебнике по русскому языку, требует комментария учителя (пояснения или переформулирования, сопровождения дополнительными иллюстративными примерами), а выполнение некоторых упражнений требует фронтального разбора образцов и очного учительского сопровождения. Кроме того, работа с учебником, а следовательно с одной формой представления информации, делает домашнее задание однообразным, не обеспечивает смену видов деятельности, подключает только один из возможных каналов восприятия - визуальный. Кроме того, неминуемо возникнет затруднение организационного характера, связанное с объёмом домашнего задания 
и временем, которое отводится на его выполнение. В среднем работа над одним заданием составляет 15-20 минут. Именно в эти хронологические рамки должно укладываться изучение теории и первичное закрепление усвоенной информации.

Из этого следует, что для методического обеспечения процесса обучения русскому языку с применением модели «перевёрнутый класс» традиционного комплекта УМК будет недостаточно. Необходимо создать библиотеку разнообразных интерактивных ресурсов, доступных дистанционно. В её структуру входят следующие блоки: 1. Теория. 2. Практика. 3. Рефлексия/оценка 4. Обратная связь.

Теоретический блок должен быть представлен объяснительными материалами в разной форме (сплошной текст и разные виды несплошного текста: таблицы, схемы, графики - визуальный канал восприятия; видеофрагменты, аудиофрагменты - аудиовизуальный канал) и заданиями, направленными на первичное закрепление темы (тестовые задания разных видов, простые интерактивные задания и проч.). Причём в рамках одного домашнего задания объяснение теории должно быть представлено в разных формах, чтобы учащиеся могли выбрать наиболее подходящий для них способ усвоения новой информации или использовать все возможные пути восприятия теоретических сведений. Теоретический блок может быть сформирован из готовых методических материалов, находящихся в свободном доступе, а также создаваться самим педагогом. Однако при подборе/составлении нужно учесть следующие содержательные и формальные требования: изучаемый материал должен быть подан эвристически (теоретические выводы на основании практических наблюдений над языковым материалом), должен реализовываться принцип проблематизации обучения (восприятие теории через систему решения проблемных вопросов); задания на закрепление должны соотноситься с видео, аудио и текстовым объяснением теории, а также должны дифференцироваться по уровню сложности; продолжительность видео и аудиофрагментов не должна превышать 5-7 минут (фрагменты большей продолжительности нужно разбивать на блоки).

Практическая часть должна содержать упражнения, направленные на применение изученной теории.

Блок рефлексии/самооценки, не входящий в структуру классического домашнего задания, является важной составляющей «кейса» домашнего задания в технологии «перевёрнутый класс». Учащимся предлагается заполнить таблицы/карточки рефлексии, которые позволяют оценивать прогресс и контролировать прохождение темы. По сути, это анкетирование (система вопросов с ранжированными ответами), которое позволяет осмыс- лить уровень достижения предметных, метапредметных и личностных результатов.

Блок «Обратной связи» может реализовываться двумя способами. Если проверка заданий автоматизирована, то учащиеся могут самостоятельно читать комментарии к своим ответам (например, такая функция есть на сервисе ЯКласс). Если проверка не автоматизирована и представлена в виде сверки с эталоном, то учащимся должна быть предоставлена форма для фиксации возникших вопросов и затруднений. Их разбор предполагается на очном занятии.

Для формирования библиотеки ресурсов (содержательная часть) для домашнего задания по русскому языку можно воспользоваться рецензируемыми/модерируемыми источниками:

1. Библиотека МЭШ (https://uchebnik.mos.ru/) (coдержит готовые сценарии уроков и атомики, из которых может быть сформировано домашнее задание: видеофрагменты уроков с объяснением теоретического материала, таблицы, схемы, иллюстративные материалы; тексты; тестовые задания, тестовые спецификации; интерактивные приложения);

2. Портал «Грамота.ру» (http://gramota.ru/) (тематический раздел «Класс»: «Учебник грамоты: орфография» и «Учебник грамоты: пунктуация», в которых содержится текстовое объяснение правил, сопровождённое интерактивным тренажёром; раздел «Интерактивный диктант»);

3. Электронное пособие «Курс русского языка», издательство «Лицей» (https://licey.net/free/4-russkii_ yazyk/) (текстовые объяснения теории по всем разделам науки о языке и сборник упражнений с ключами);

4. ЯКласс (https://www.yaklass.ru/) (интерактивный сервис с очень широким опционалом: тексты по теории, интерактивные задания разных типов, тренажёры и блок контрольных вопросов, система обратной связи (выставление и хранение оценок за выполненные задания);

5. Решу ОГЭ/ЕГЭ (https://rus-oge.sdamgia.ru/) (тренажёр экзаменационных заданий) и некоторые другие.

Вопрос технического обеспечения домашнего задания возможно решить средствами бесплатных/частично бесплатных онлайн платформ, таких как ЯКласс, onlinetestpad.com, LearningApps.org и другие.

Пример формирования домашнего задания для урока по технологии «Перевёрнутый класс».

Тема - «Правописание приставок пре- и при-» 
Домашнее задание.

1. Прослушать фрагмент передачи «Радионяня», посвящённый правилу правописания приставок пре- и при- (подробный разбор правила на богатом иллюстративном материале; продолжительность фрагмента - 6 минут) https://uchebnik.mos.ru/ catalogue/material_view/atomic_objects/5219597

2. Заполнить шаблон текста правила:

а) Правописание приставок пре- и при- зависит от_(значения)_.

b) Приставка при- обозначает: _(присоединение, приближение, близость, неполное действие)

с) Приставка пре- по своему значению может быть близка__(слову очень)__или (приставке -пере).

3. Выполнить тренировочное задание в приложении (распределить слова в соответствии с выбором гласной, автоматическая проверка) https:// uchebnik.mos.ru/material/app/47235;

4. Выполнить контрольное задание на первичное закрепление теории https://uchebnik.mos.ru/exam/ test/training_spec/13643/task/1 (два тестовых вопроса на усвоение теории и два практических во- проса, автоматическая проверка).

5. Дополнительные материалы:

а. текстовое объяснение теории и тренажёр http://gramota.ru/class/coach/tbgramota/45_62

b. текстовое объяснение теории и упражнения с ключами https://licey.net/free/4-russkii_ yazyk/39-kurs_russkogo_yazyka_fonetika__ slovoobrazovanie_morfologiya_i_orfografiya/ stages/649-26_pravopisanie_pristavok.html и https://licey.net/free/4-russkii_yazyk/42-kurs_ russkogo_yazyka_uprazhneniya/stages/846-26_ pravopisanie_pristavok.html

В заключение, следует сказать, что образование в наши дни - это та сфера, в которой происходят самые стремительные изменения и трансформации. В связи с этим, обязательным условием успешной педагогической деятельности становится освоение современных образовательных технологий и методик, нацеленных на достижение перспективных образовательных результатов. Возможно, модели смешанного обучения - это тот самый ключ к успешной и эффективной организации познавательной и развивающей деятельности современных учащихся.

\section{ЛИТЕРАТУРА}

1. Андреева Н.В., Рождественская Л.В., Ярмахов Б.Б. Шаг школы в смешанное обучение. Рыбаков фонд. М.: 2016

2. Букатов В.М. Клиповые изменения в восприятии, понимании и мышлении современных школьников - досадное новообразование «постиндустриального уклада» или долгожданная реанимация психического естества? // «Актуальные проблемы психологического знания» - 2018. - № 4 (49).

3. Краснова Т.И. Смешанное обучение: опят, проблемы и перспективы // В мире научных открытий. 2014. № 11. С. 10-26.

(c) Цветкова Любовь Алексеевна (tsvetkova.liubov1986@gmail.com). 